\title{
Correction to: Short-term outcome of laparoscopic versus robotic ventral mesh rectopexy for full-thickness rectal prolapse. Is robotic superior?
}

\author{
Rao K. Mehmood ${ }^{1} \cdot$ Jody Parker $^{1} \cdot$ L. Bhuvimanian ${ }^{2} \cdot$ Eyas Qasem $^{1} \cdot$ Ahmed A. Mohammed $^{1} \cdot$ Muhammad Zeeshan $^{3}$. \\ Kirsten Grugel $^{2} \cdot$ Paul Carter $^{2} \cdot$ Shakil Ahmed $^{2}$
}

Published online: 9 February 2019

(C) Springer-Verlag GmbH Germany, part of Springer Nature 2019

\section{Correction to: Int J Colorectal Dis (2014) 29:1113-1118 https://doi.org/10.1007/s00384-014-1937-4}

The authors wish to clarify the following points that were incorrectly stated in the published original version of this article:

- This was a personal series of consecutive patients, all operated on by Ahmed S, across more than one centres.

- As correctly stated in the abstract and the discussion, but misstated in the methods section, there was no randomization.

- It was a personal series not a trial and therefore no ethics or other approvals were necessary.

Publisher's note Springer Nature remains neutral with regard to jurisdictional claims in published maps and institutional affiliations.

The online version of the original article can be found at https:/doi.org/ 10.1007/s00384-014-1937-4

Rao K. Mehmood

raodilmeer@yahoo.com

1 Department of Surgery, Betsi Cadwaladr University Health Board, Ysbyty Glan Clwyd, Rhyl, North Wales LL18 5UJ, UK

2 Department of Colorectal Surgery, Royal Liverpool and Broadgreen University Hospital NHS Trust, University of Liverpool,

Liverpool L7 8XP, UK

3 University Hospital of North Cumbria, Carlisle, UK 